\title{
Use of reactance to estimate
}

\section{transpulmonary resistance}

\author{
M.K. Johnson*, M. Birch", R. Carter*, J. Kinsella* and R.D. Stevenson*
}

ABSTRACT: This study examines the relationship of respiratory system resistance (Rrs) and reactance $(X \mathrm{rs})$ measured by forced oscillometry with transpulmonary resistance $(R L)$ measured by oesophageal manometry.

Simultaneous forced oscillometry using a single frequency of $5 \mathrm{~Hz}$ and oesophageal manometry were performed on five asthmatics during bronchoprovocation. The data obtained were used to derive prediction equations for $R \mathbf{L}$ from oscillometric parameters, which were tested on a further six asthmatics and 35 nonasthmatic subjects.

In the first five asthmatic subjects, $R$ L correlated more strongly with Xrs than with $R$ rs. In the second set of asthmatics, $R \mathrm{~L}$ ranged $0.0005-4.57 \mathrm{kPa} \cdot \mathrm{s} \cdot \mathrm{L}^{-1}$, with a median of $0.21 \mathrm{kPa} \cdot \mathrm{s} \cdot \mathrm{L}^{-1}$. The $R L$ values predicted from $X$ rs showed a mean \pm SD difference of $-0.067 \pm 0.25 \mathrm{kPa} \cdot \mathrm{s} \cdot \mathrm{L}^{-1}$ compared with the values measured in this set of patients. $X r s$ in subjects with other respiratory conditions appeared to follow the same relationship with $R L$ as in asthmatics. Lumped element modelling suggested that the linear relationship between $X r s$ and $R L$ was a consequence of the increasing contribution of central and upper airway wall shunts as peripheral airway resistance rose, and that this effect was much larger than that due to changes in static elastance.

In conclusion, the reactance of the respiratory system can predict transpulmonary resistance more accurately than can the resistance of the respiratory system.

KEYWORDS: Airway hyperresponsiveness, airway obstruction, forced oscillation technique, resistance

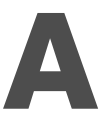
s a pulmonary function test for measuring resistance, the forced oscillation technique (FOT) has several advantages [1]. It is a passive manoeuvre, requiring only tidal breathing from the subject, and can provide continuous measurement of the resistance of the respiratory system (Rrs), delineating within-breath changes with sub-second resolution. It also has limitations. First, as distal airways obstruction increases, there is worsening agreement of Rrs with transpulmonary resistance $(R \mathrm{~L})$ measured by oesophageal manometry [2]. Under these conditions, Rrs is underestimated because the upper airway wall, which acts as an impedance in parallel (or shunt) with the lower airway, becomes increasingly important. Secondly, it is less useful for diagnosis as any pathology produces a similar pattern of abnormality in oscillometric results, although differing in degree [1]. Despite these drawbacks, the FOT performs similarly to standard tests in many areas (e.g. bronchodilator reversibility [3] and bronchial challenge testing [4]). In order to guarantee its wider use, it needs to surpass current techniques or be useful in areas less well furnished with tests.
The agreement between $R$ rs and $R \mathrm{~L}$ can be improved by the use of a head plethysmograph [5], but this approach is cumbersome. A further recent proposal was the use of changes in admittance (the reciprocal of impedance) during bronchoprovocation [6]. Theoretically, this quantity should be independent of the effect of upper airway wall shunt, and the results obtained from standard oscillometric equipment compared with the head plethysmograph, although not identical, supported this claim. However, admittance could only be used to predict changes in resistance rather than its absolute value. The reactance of the respiratory system $(\mathrm{Xrs})$, which represents the spectral relationship between the pressure component out of phase with flow and the flow, would not a priori be considered a measure of airways obstruction because it is thought to reflect inertive and elastic properties. However, $\mathrm{Xrs}$ decreases (becomes more negative) as airways obstruction increases, and, in several studies, it appeared to correlate more strongly with forced expiratory volume in one second (FEV1) and plethysmographic airway resistance (Raw) than did Rrs [7-9].
AFFILIATIONS

*Dept of Respiratory Medicine Glasgow Royal Infirmary, Glasgow and \#Dept of Clinical Physics, Royal London Hospital, London, UK.

\section{CORRESPONDENCE}

M.K. Johnson

Dept of Respiratory Medicine

Gartnavel General Hospital

1053 Great Western Road

Glasgow

G12 OA

UK

E-mail: johnson7@which.ne

Received:

July 092004

Accepted after revision:

February 022005

SUPPORT STATEMENT

This study was supported by the Scottish Executive (Edinburgh, UK). 
In the present study, simultaneous oesophageal manometry and the within-breath FOT at $5 \mathrm{~Hz}$ were performed. The aim was to assess the relationship between resistance derived from oesophageal manometry $(R \mathrm{~L})$ and FOT parameters, including both those conventionally associated with resistance (Rrs) and those not conventionally associated with resistance (Xrs).

\section{METHOD}

\section{Study design}

The FOT and oesophageal manometry were performed simultaneously on 11 asthmatic patients at several points during a histamine challenge test. The data generated from the first five asthmatics were used to investigate the relationship between $R \mathrm{~L}$ and FOT variables. A linear model to predict the absolute value of $R L$ was generated from the data using the single most strongly correlated FOT variable. Then, data from the remaining six asthmatics were used to assess the fit of the predictive model. Finally, single-point measurements were performed in both normal subjects and others with a range of respiratory conditions (chronic obstructive pulmonary disease (COPD), interstitial lung disease (ILD), chest wall disease and respiratory muscle myopathy) in order to assess whether this behaviour was also seen outside the context of asthma. Ethical approval for this study was obtained from the Local Research \& Ethics Committee of Glasgow Royal Infirmary (Glasgow, UK).

\section{Study subjects}

The normal and asthmatic subjects were drawn from the staff of the Depts of Respiratory Medicine and Anaesthesia of Glasgow Royal Infirmary. The first five asthmatic subjects exhibited a mean \pm SD age of $39 \pm 7.4$ yrs, FEV1 of $93 \pm 10 \%$ of the predicted value and FEV1/forced vital capacity (FVC) ratio of $70 \pm 5.1 \%$, and the second six an age of $32 \pm 3.0 \mathrm{yrs}, \mathrm{FEV} 1$ of $92 \pm 15 \%$ pred and FEV1/FVC of $74 \pm 4.9 \%$. All were nonsmoking males who satisfied the British Thoracic Society (BTS) definition of asthma [10]. Otherwise, the subjects were volunteers from the respiratory outpatient clinics of Glasgow Royal Infirmary (table 1). The subjects with COPD satisfied the BTS definitions for this condition [11]. All of the subjects with ILD showed computed tomographic scan evidence of diffuse

\begin{tabular}{|c|c|c|c|}
\hline & Subjects (males) $n$ & FEV $1 \%$ pred & $\mathrm{FEV}_{1} / \mathrm{FVC} \%$ \\
\hline Normal & $7(5)$ & $97 \pm 6.7$ & $84 \pm 3.3$ \\
\hline COPD & $9(8)$ & $54 \pm 22$ & $40 \pm 8.9$ \\
\hline ILD $\#$ & $9(4)$ & $82 \pm 23$ & $73 \pm 7.8$ \\
\hline Chest wall disease & $8(3)$ & $32 \pm 5.0$ & $63 \pm 23$ \\
\hline Myopathy $^{+}$ & $2(0)$ & $63 \pm 23$ & $81 \pm 13$ \\
\hline
\end{tabular}

Data are presented as mean $\pm \mathrm{SD}$, unless otherwise stated. FEV 1 : forced expiratory volume in one second; \% pred: \% predicted; FVC: forced vital capacity; COPD: chronic obstructive pulmonary disease; ILD: interstitial lung disease. \#: idiopathic pulmonary fibrosis $(n=3)$, connective tissue disease $(n=3)$, sarcoidosis $(n=1)$, silicosis $(n=1)$ and hypersensitivity pneumonitis $(n=1)$; ${ }^{\prime}$ : kyphoscoliosis $(n=4)$, thoracoplasty $(n=3)$ and pneumonectomy $(n=1){ }^{+}$: mitochondrial myopathy $(n=1)$ and diaphragmatic palsy $(n=1)$. parenchymal lung disease and five were biopsy proven. The subjects with chest wall disease and myopathy used chronic nocturnal noninvasive ventilation for these conditions.

\section{Methods and analysis}

Histamine challenge test

The histamine challenge test was performed as previously described [12]. Baseline spirometry, oesophageal manometry and the FOT were performed. After diluent (normal saline), histamine (Tayside Pharmaceuticals, Dundee, UK) was delivered in doubling concentrations using a jet nebuliser (MicroNeb Nebuliser; Lifecare Hospital Supplies, Market Harborough, UK) driven by an airflow of $8 \mathrm{~L} \cdot \mathrm{min}^{-1}$ (Aquilon Nebuliser System; AFP Medical, Rugby, UK) through a face mask (Duo Mask Adult; Lifecare Hospital Supplies), and inhaled for 2 min of tidal breathing with the nose clipped. The starting concentration of histamine ranged 0.0625 $0.5 \mathrm{mg} \cdot \mathrm{mL}^{-1}$. Between doses of histamine, two simultaneous recordings, each of $1 \mathrm{~min}$ in duration, were made of oesophageal manometry and FOT parameters. The test was stopped when FEV1 dropped to $<60 \%$ of baseline or at a maximum concentration of histamine of $16 \mathrm{mg} \cdot \mathrm{mL}^{-1}$.

\section{Oesophageal manometry}

Pleural pressure was estimated using an oesophageal balloon catheter (Ackrad Laboratories Inc., Cranford, NJ, USA). This was a polyvinyl chloride catheter (length $87 \mathrm{~cm}$; size $5 \mathrm{~F}$ ) with a balloon (length 9-10 cm; circumference $22-25 \mathrm{~mm}$; wall thickness $0.025-0.05 \mathrm{~mm}$ ), which, following anaesthesia with $4 \%$ lidocaine, was inserted via a nostril into the distal third of the oesophagus; a satisfactory position was confirmed using the occlusion test [13]. Oesophageal (Poes) and airway opening $(P$ ao $)$ pressure were recorded using piezoelectric transducers (Honeywell 26PCA $( \pm 7 \mathrm{kPa})$; Honeywell, Morristown, NJ, USA, and Sensortechnics PXL0025DN $( \pm 2.5 \mathrm{kPa})$; Sensortechnics, Munich, Germany, respectively). Gas flow $\left(V^{\prime}\right)$ was measured using a heated-screen pneumotachograph (Hans Rudolph 3700A ( $\left.\pm 160 \mathrm{~L} \cdot \mathrm{min}^{-1}\right)$; Hans Rudolph, Kansas City, MO, USA). The pressure drop across the pneumotachograph was measured using a piezoelectric differential pressure transducer (Sensortechnics PXL02X5DN $( \pm 0.25 \mathrm{kPa})$; Sensortechnics). The common mode rejection ratio of the differential transducer in its measurement configuration was $>60 \mathrm{~dB}$ across the measurement bandwidth. The frequency responses of the three pressure signals were determined up to $24 \mathrm{~Hz}$ by simultaneously applying the same pressure to each input, and any differences were compensated for digitally. Data were excluded for breaths corrupted by swallowing artefacts. $V^{\prime}$ was converted from ambient temperature and pressure, saturated, to body temperature and ambient pressure, saturated.

Values of $R \mathrm{~L}$ were calculated during inspiration $(R \mathrm{~L}, \mathrm{I})$ and expiration $(R L, E)$ for each breath. For comparisons between asthmatics, least-squares multiple linear regression (MLR) was applied to the following model:

$$
P_{\text {oes }}-P_{\text {ao }}=P_{0}+E \text { dyn } V+R \mathrm{~L}, \mathrm{I} V^{\prime} \mathrm{I}+R_{\mathrm{L}, \mathrm{E}} V^{\prime} \mathrm{E}
$$

where Edyn is dynamic elastance, $V$ volume, $P_{0}$ a constant and $V^{\prime} \mathrm{I}$ and $V^{\prime} \mathrm{E}$ flow during inspiration and expiration, respectively, and were otherwise set to zero [14]. 
The fit achieved by the MLR model to transpulmonary pressures was reasonable. The median (interquartile range) $\mathrm{R}^{2}$ generated by the MLR analysis was $0.94(0.89-0.97)$. For comparisons between asthmatic and nonasthmatic subjects, least-squares regression was used to calculate $R \mathrm{~L}$ after elastic pressure changes were removed by the Mead-Whittenberger technique [15]. $V$ was obtained by integrating $V^{\prime}$, and volume drift was corrected by forcing zero volume change between equivalent points at the beginning and end of the 1-min recording. Each result was the mean over $1 \mathrm{~min}$.

\section{Forced oscillation technique measurements}

The machine used in the present studies was designed by BIRCH et al. [16]. While the subject performed tidal breathing through a mouthpiece with nose occluded and cheeks supported, it measured within-breath impedance of the respiratory system $(\mathrm{Zrs})$ using a sinusoidal excitation signal of $5-\mathrm{Hz}$ frequency generated by a loudspeaker. Zrs was then further divided into components in which pressure and flow are in phase (resistance (Rrs)) and $90^{\circ}$ out of phase (reactance $(X \mathrm{rs}))$. A bias flow of $0.25 \mathrm{~L} \cdot \mathrm{s}^{-1}$ of air was fed into the breathing circuit in order to minimise rebreathing. The measurement of $P$ ao and $V^{\prime}$ were as described for oesophageal manometry. The equipment was calibrated for flow using a standard rotameter (Platon Instrumentation, Bramley, UK), pressure using an electronic pressure meter (Comark C9551; Comark, Stevenage, UK) and resistance using three wire-mesh resistors over the range $0.2-2.0 \mathrm{kPa} \cdot \mathrm{s} \cdot \mathrm{L}^{-1}$. Calculation of $\mathrm{Zrs}$ was performed by software. The breathing and forcing waveforms were separated using a moving average filter [17]. Zrs was calculated from the forcing waveforms using the method based upon power spectra [18] further adapted for within-breath analysis [17]. This provided $R \mathrm{rs}$ and $X \mathrm{rs}$, which were a stepwise function of time at 0.2 -s intervals. The within-breath $Z$ rs values were low-pass filtered to remove biological noise using a Butterworth eight-pole filter with a cut-off frequency of $2 \mathrm{~Hz}$. The $R r s$ and $X_{r s}$ values were averaged over the inspiratory $(R r s, I, X r s, I)$ and expiratory $(R r s, E, X r s, E)$ phases of each breath to give separate values for the two phases of the respiratory cycle (fig. 1). The values from a 1-min recording were then averaged.

\section{Data handling}

Poes, $P$ ao and $V^{\prime}$ were passed from the transducers into an analogue-to-digital data acquisition system (MP100A; BIOPAC Systems Inc., Goleta, CA, USA). The signals were sampled at a frequency of $200 \mathrm{~Hz}$ with 16-bit resolution, displayed and stored on an IBM-compatible personal computer using systemspecific software (AcqKnowledge 3.7; BIOPAC Systems Inc.), and analysed using the MATLAB numeric computing environment (The MathWorks Inc., Natick, MA, USA).

\section{Statistical analysis}

Correlation was assessed using Pearson's r correlation coefficients. Prediction equations were generated by least-squares linear regression. Agreement of the prediction models with absolute values was assessed using the analysis proposed by BLAND and ALTMAN [19]. The repeatability of measurements was calculated as a coefficient of variation by expressing the SD of repeated measurements as a percentage of the mean. Mean \pm SD was used for baseline pulmonary function data.

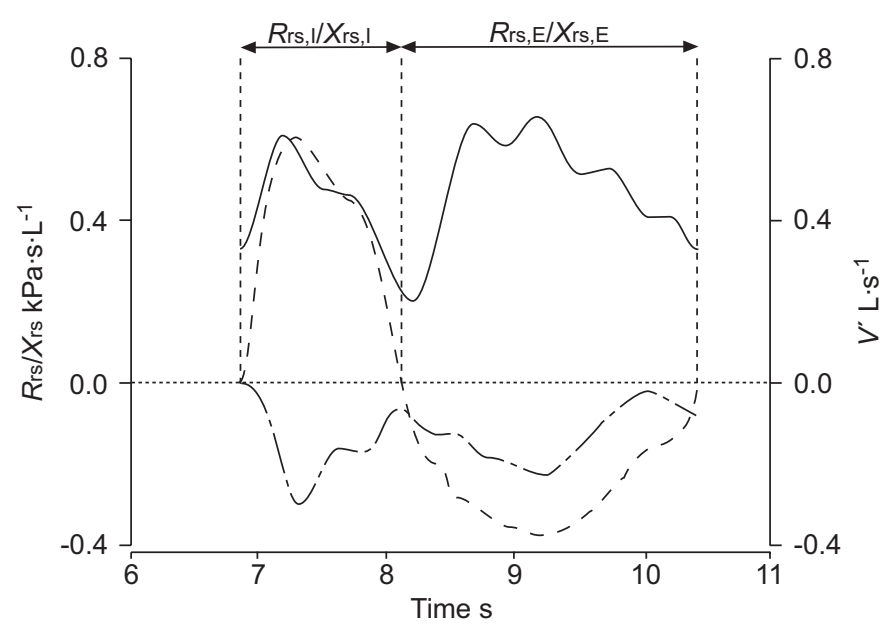

FIGURE 1. Within-breath flow ( $\left.V^{\prime} ;----\right)$ and respiratory system resistance (Rrs; - - ) and reactance (Xrs; _ - - ) over one respiratory cycle in one of the asthmatic subjects at the midpoint of the histamine challenge test. Inspiratory Rrs $(R r s, I)$ and $X_{r s}\left(X_{r s}, I\right)$ were calculated for each breath by averaging inspiratory values. Expiratory $R_{r s}(R r s, E)$ and $X_{r s}\left(X_{r s}, E\right)$ were similarly obtained from expiratory values.

\section{RESULTS}

\section{First set of asthmatic subjects}

Bronchoprovocation tests in the first five asthmatics produced 96 measurements. Rrs,I progressively underestimated RL,I as airway obstruction increased (fig. 2a), leading to a divergence of the curve of the scatter plot from a straight line. The size of the error due to upper airway wall shunt was variable, causing the scatter plot to fan out at high values.

The oscillometric parameter most strongly correlated with RL,I was inspiratory $X_{\mathrm{rs}}\left(\mathrm{Xrs}_{\mathrm{rs}} \mathrm{I}\right.$; table 2$)$. The strength of this association was particularly striking, as illustrated in figure $2 b$. A tight linear relationship was preserved until the highest observed values of $X$ rs. A prediction equation for $R$ L,I was therefore derived from $\mathrm{Xrs}$, I.

\section{Second set of asthmatic subjects}

Bronchoprovocation testing in the second set of asthmatics led to a further 123 data points. $R \mathrm{~L}$ values in this group ranged $0.0005-4.57 \mathrm{kPa} \cdot \mathrm{s} \cdot \mathrm{L}^{-1}$, with a median of $0.21 \mathrm{kPa} \cdot \mathrm{s} \cdot \mathrm{L}^{-1}$. The values were skewed towards the normal range because the airways of the six subjects were unconstricted, except for a few points towards the end of each histamine challenge test. The lower limit of the range measured is physically unrealistic and a consequence of the significant error involved in measuring normal values of $R \mathrm{~L}$ by oesophageal manometry.

The accuracy of the prediction model was tested on these data and the results are shown in figure 3 . The equivalent results using absolute $R$ rs are shown for comparison. The prediction model using $X \mathrm{rs}, \mathrm{I}$ is clearly more accurate at predicting $R \mathrm{~L}, \mathrm{I}$. In particular, agreement is maintained until a relatively high value of $R \mathrm{~L}, \mathrm{I}\left(\sim 2.5 \mathrm{kPa} \cdot \mathrm{s} \cdot \mathrm{L}^{-1}\right)$.

\section{Nonasthmatic subjects}

Measurements were then performed on subjects with respiratory conditions other than asthma. A pair of duplicate readings was obtained for each of these subjects and the relationship 


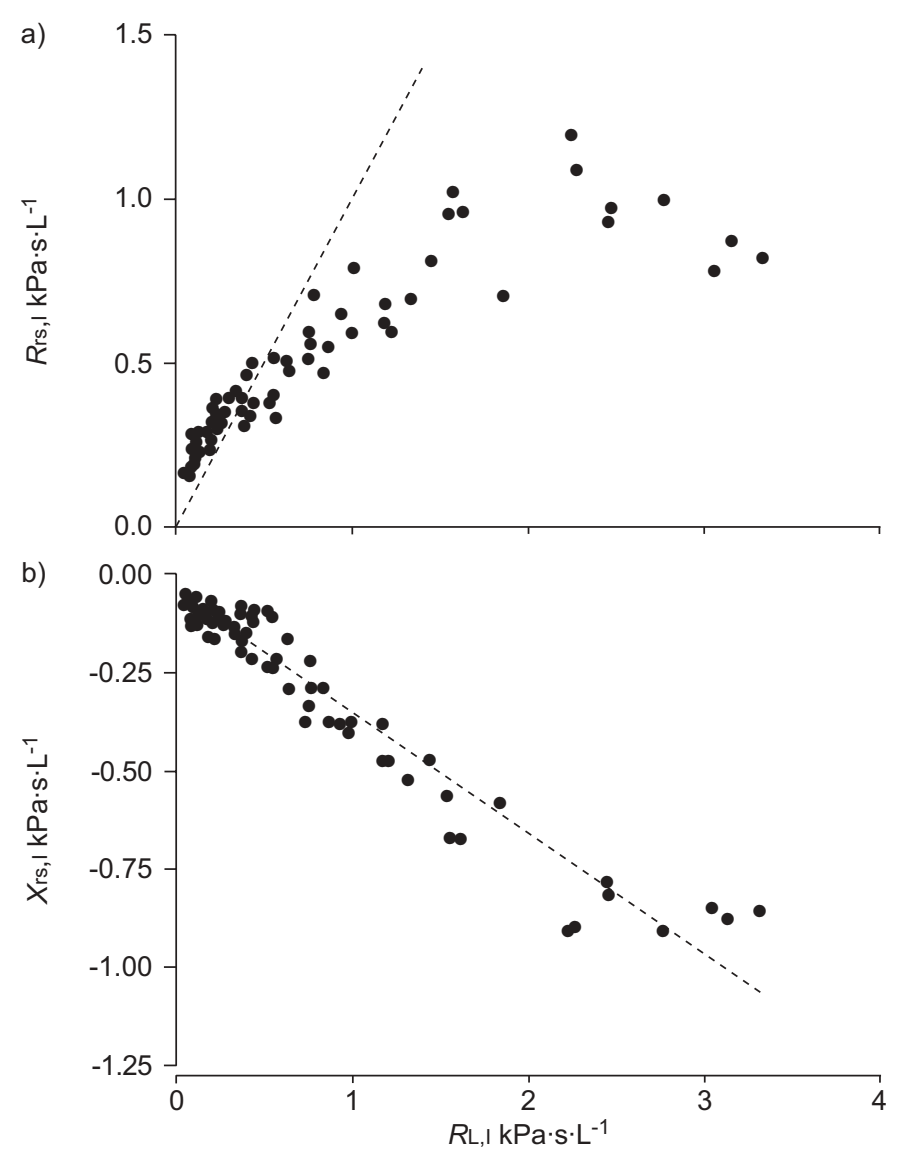

FIGURE 2. Forced oscillation technique data from the first five asthmatic subjects showing a) inspiratory resistance of the respiratory system (Rrs,I) and b) inspiratory reactance of the respiratory system (Xrs,I). Inspiratory transpulmonary resistance $(R L, I)$ was calculated using least-squares multiple linear regression applied to a model which allowed different inspiratory and expiratory resistances. The line of best fit to the $X_{r s, I}$ data is $X_{r s, I}=-0.3037 R L, I-0.046\left(r^{2}=0.94\right)$.

between $R \mathrm{~L}$ and oscillometric variables compared as before (fig. 4). Although scatter was greater, the results can be seen to follow essentially the same linear relationship as obtained for pure asthmatics. In these subjects, the mean \pm SD difference between measured $R \mathrm{~L}, \mathrm{I}$ and that predicted from $\mathrm{Xrs,I}$ was $0.034 \pm 0.37 \mathrm{kPa} \cdot \mathrm{s} \cdot \mathrm{L}^{-1}$.

\begin{tabular}{|c|c|c|c|}
\hline \multirow[t]{2}{*}{ TABLE 2} & \multicolumn{3}{|c|}{$\begin{array}{l}\text { Pearson correlation coefficients }\left(r^{2}\right) \text { relating forced } \\
\text { oscillation technique parameters to } \\
\text { transpulmonary resistance }(R L) \text { in the first five } \\
\text { asthmatic subjects }\end{array}$} \\
\hline & Rrs & $\mathrm{Xrs}_{\mathrm{rs}}$ & Zrs \\
\hline$R \mathrm{~L}, \mathrm{I}$ & 0.79 & 0.94 & 0.88 \\
\hline$R \mathrm{LLE}$ & 0.59 & 0.92 & 0.83 \\
\hline
\end{tabular}

$R L, I$ inspiratory $R L$; $R L$,E: expiratory $R L$; $R r s:$ resistance of the respiratory system; $X_{r s}$ : reactance of the respiratory system; Zrs: impedance of the respiratory system. All p-values are $<0.0001$.

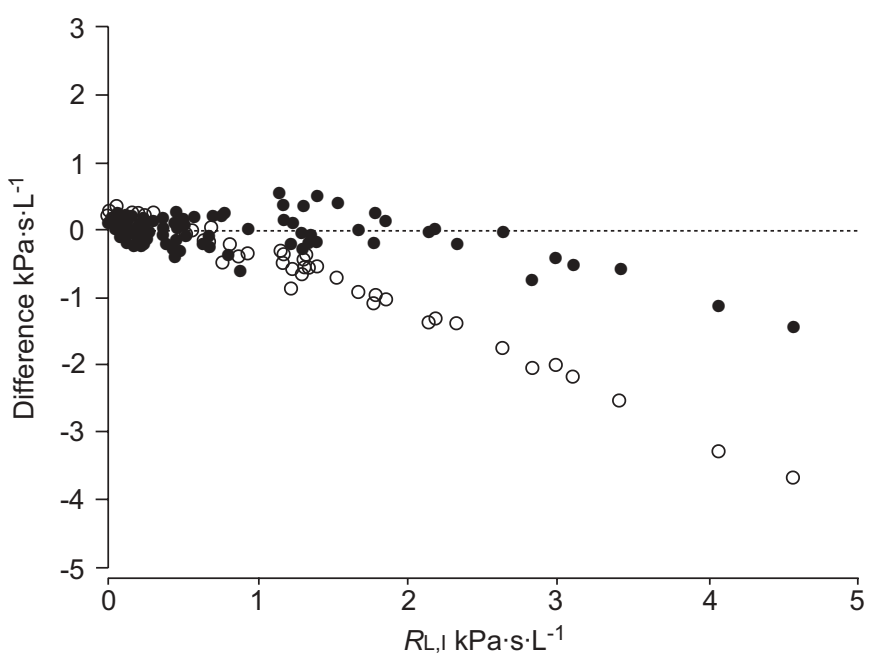

FIGURE 3. Data from the second set of six asthmatic subjects showing the accuracy of the prediction model derived from inspiratory reactance of the respiratory system (Xrs,l) for predicting inspiratory transpulmonary resistance $(R L, I)$. This is a scatter plot of the difference between predicted values of $R L, I$ (from equation for fig. $2 \mathrm{~b}$, derived from the first five asthmatics) and measured $R L, I$ against measured $R L, I(\bullet)$. For comparison, the same plot using inspiratory resistance of the respiratory system $(O)$ is also shown. The mean \pm SD difference for values predicted from $X_{\mathrm{rs}, \mathrm{l}}$ is $-0.067 \pm 0.25 \mathrm{kPa} \cdot \mathrm{s} \cdot \mathrm{L}^{-1}$.

\section{DISCUSSION}

In the present study, a less conventional but carefully considered approach has been taken to the use of oscillometric data. Rrs and Xrs were calculated as a function of time and the results separated into mean inspiratory and expiratory values. The focus was on inspiratory data as the principal interest was active resistive work. If expiratory values were used, similar results were obtained, although the correlation coefficients dropped in value (table 2), probably due to expiratory flow

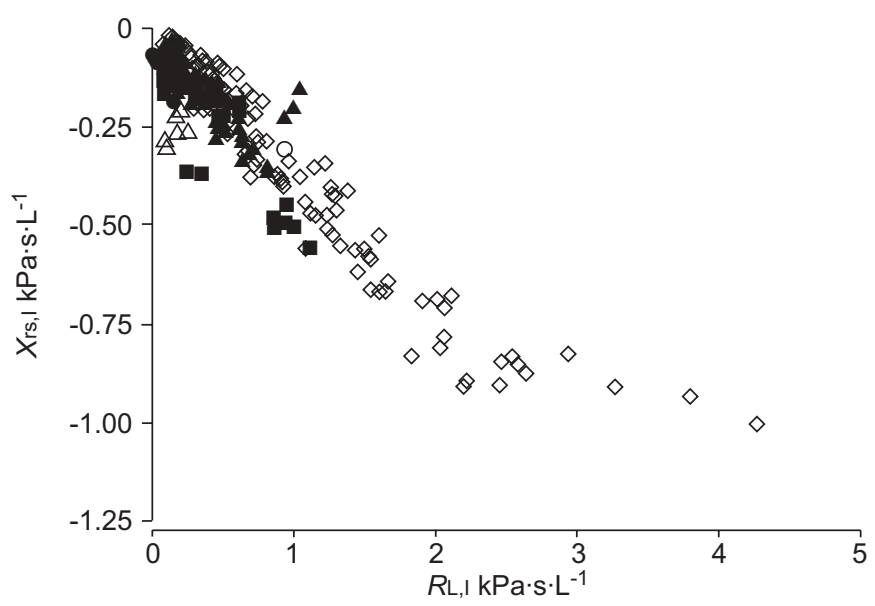

FIGURE 4. Inspiratory reactance of the respiratory system (Xrs,I) measured using the forced oscillation technique as a function of inspiratory transpulmonary resistance $(R L, I)$ in all subjects ( $\bullet$ : normal subjects; $\diamond$ : asthma; $\mathbf{\square}$ : chest wall disease; $\mathbf{\Lambda}$ : chronic obstructive pulmonary disease; $\triangle$ : interstitial lung disease; $O$ : myopathy). RL,I was calculated using least-squares regression/MeadWhittenberger technique. 
limitation. A single frequency of $5 \mathrm{~Hz}$ was used as a compromise between reducing errors attributable to respiratory frequency and reducing the impact of upper airway wall shunt. Finally, the usefulness of variables other than Rrs (i.e. Xrs and $Z_{\mathrm{rs}}$ ) in estimating resistive properties was analysed. There were three interesting and perhaps surprising results. First, the strongest predictor of $R \mathrm{~L}$ was not $R \mathrm{rs}$ but $\mathrm{Xrs}$ (table 2). Secondly, the relationship between $X r$ and $R L$ appeared to be linear. Thirdly, the results appeared to lie largely on the same curve, irrespective of the nature of the underlying disease process (fig. 4).

Why is there a strong correlation between $\mathrm{Xrs}_{\mathrm{rs}}$ and RL? It is clearly not an artefact of the present measurements as Xrs is known to become more negative with increasing airways obstruction. This has been shown in the settings of both COPD [20] and asthma [21], and led to its proposal as an alternative measure during bronchial challenge testing [22]. The relationship between Xrs and Raw/FEV1 has been found to be stronger than for Rrs [7-9].

$X \mathrm{rs}$ is composed of contributions from both inertance and dynamic elastance (Edyn); Edyn is dominant at a forcing frequency of $5 \mathrm{~Hz}$. Edyn is larger than static elastance, the latter being measured under steady-state conditions and describing only the static elastic properties. The difference between the two is accentuated by increasing flow rates or airway obstruction [23] and is attributable to several phenomena, viscoelasticity [24], time-constant inhomogeneity (Otis effect) [25] and shunting by either the upper [18] or central [26] airway walls (Mead effect). The contribution from viscoelasticity occurs even in normal subjects and represents the timedependent resistive and elastic behaviour of the lung and chest wall tissues. Time-constant inhomogeneity describes heterogeneity of the mechanical properties in different areas of the lungs, usually as a consequence of underlying pathology, which leads to regional variations in rates of emptying of the lungs and the potential for air recirculation. Central and upper airway wall shunting occurs when the impedance of the lung periphery becomes comparable to the tissue impedance of the central and upper airway walls, usually as a consequence of increasing distal airways obstruction or airway closure. Here, upper airway refers to supraglottal and central airway to immediate subglottal structures.

Simulation studies have been performed to evaluate the relative influence of viscoelasticity, airway wall shunting and timeconstant inhomogeneity on Edyn. A sophisticated approach was taken by LUTCHEN and coworkers [27, 28], who investigated Edyn from breathing frequency to $5 \mathrm{~Hz}$ using a morphometric model of the lung. They predicted that increased bronchoconstriction could increase Edyn in several ways. First, homogeneous bronchoconstriction could produce a large increase in Edyn by central airway wall shunting [27]. Secondly, severe inhomogeneous bronchoconstriction (with a $>80 \%$ reduction in calibre in a small number of airways) could produce a similarly large increase in Edyn by the mechanism of time-constant inhomogeneity [28]. The effect of viscoelasticity was detectable but more modest [27]. Support for the significance of heterogeneous bronchoconstriction is also present in a second model generated by ANAFI et al. [29], which simulated the physical behaviour of a single peripheral airway, taking into account airway flow and parenchyma and smooth muscle properties. This predicted that a constricted airway had two stable states, open and almost closed, and led automatically to a two-compartment lung model and the situation of heterogeneous airways obstruction. The relationship between peripheral airway resistance $(R \mathrm{p})$ and $E$ dyn predicted by this model when the proportion of closed airways was increased from zero to almost complete is shown in figure 5 .

Less complex lumped-element models representing timeconstant inhomogeneity and airway wall shunting have been used extensively in previous oscillometric studies to interpret $R$ rs and $X r s$ data, usually presented as a function of frequency. The common conclusion of most of these studies is that a model incorporating central airway wall compliance (Mead effect) fits the data better than one proposing parallel pathways (Otis effect), both qualitatively and as regards realistic physical values for the model coefficients [18, 30-34]. Further support for the significance of the Mead effect comes from data on expiratory flow limitation. This is the extreme case of the Mead model as the oscillometric forcing signal is unable to pass the flow-limited airway segments, and, instead, is dissipated in the parallel impedances represented by the central and upper airway walls. In the recent study of DELLACÀ et al. [35], Xrs dropped dramatically in the presence of expiratory flow limitation, confirmed by oesophageal pressure-flow loops. They were again able to simulate this effect using a lumpedelement model, which allowed an airway wall shunt in parallel with airway and tissue compartments. The effect of expiratory flow limitation was reproduced when the resistance of the airways was increased from 0.05 to $25 \mathrm{kPa} \cdot \mathrm{s} \cdot \mathrm{L}^{-1}$.

Bronchoconstriction could also increase Edyn by a direct effect on static tissue elastance due to changes in tissue properties [36] or airway closure, but the magnitude of this component is uncertain and difficult to unravel from airway effects [27]. Studies attempting to partition airway and tissue properties conclude that the effect exists but is probably a lesser component of the increase in Edyn seen during bronchoconstriction [34, 37].

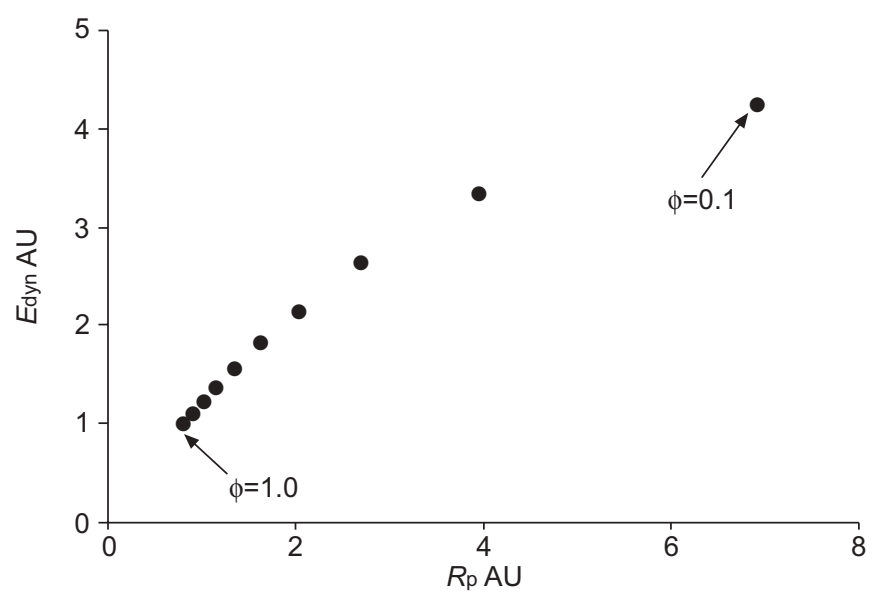

FIGURE 5. Relationship between peripheral airway resistance $(R p)$ and dynamic elastance (Edyn) using the two-compartment model proposed by ANAFI et al. [29] when the proportion of open airways $(\phi)$ is decreased from 1.0 to 0.1 in steps of 0.1 . AU: arbitrary unit. 
In order to determine the relative contributions of the different mechanisms to the decrease in $X \mathrm{rs}$ with increasing $R \mathrm{~L}$, the scenario was simulated using a lumped-element model at a single frequency of $5 \mathrm{~Hz}$, which incorporated time-constant inhomogeneity and both central and upper airway wall shunting. This model is described in detail in the Appendix. Representative values from the literature were chosen for the model parameter values, and the only variable was $R \mathrm{p}$, which was allowed to range over the values seen for $R \mathrm{~L}$. The simulation results are compared to the experimental data from the first five asthmatic subjects in figure 6 . It can be seen that the model reproduces the qualitative behaviour of the data with the parameter values chosen and is also a reasonably accurate quantitative fit.

The simulation was then repeated incorporating one mechanism at a time; the results are shown in figure $7 \mathrm{a}$. Heterogeneous parallel pathways alone did not reproduce the Xrs behaviour, even when the time constants between the two pathways differed by several orders of magnitude. In
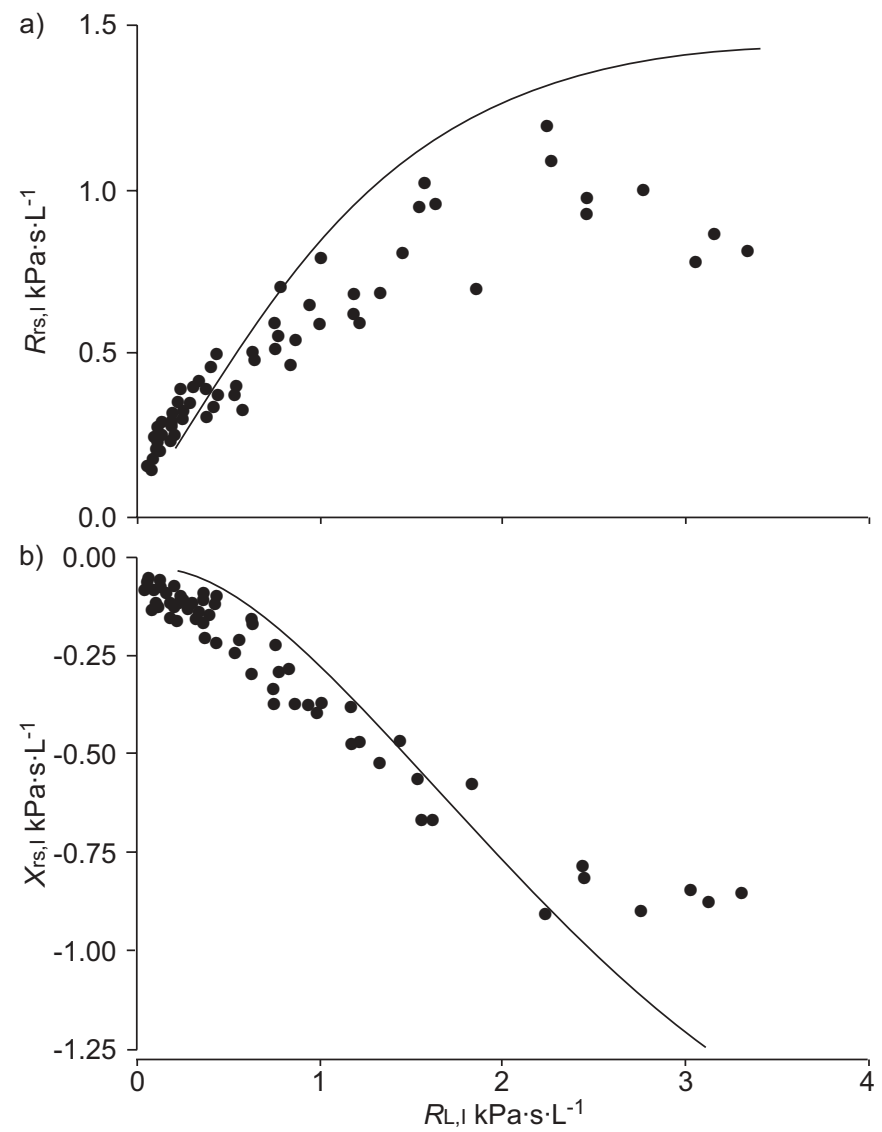

FIGURE 6. Results of lumped-element modelling $(-)$ compared with experimental data $(\bullet)$ from the first five asthmatic subjects for a) inspiratory resistance of the respiratory system (Rrs,I) and b) inspiratory reactance of the respiratory system (Xrs,I). In the simulation, inspiratory transpulmonary resistance $(R L, I)$ is replaced by the sum of the serial resistances of the lumped-element model, which was calculated from the sum of the central airway resistance $(R c)$, chest wall resistance $(R \mathrm{w})$ and peripheral airway resistance $(R \mathrm{p}) . R \mathrm{c}$ and $R \mathrm{w}$ were constant and are given in table 3 . $R$ p represents the real part of the sum of the impedances of the two peripheral pathways ( $Z \mathrm{p} 1$ and $Z \mathrm{p} 2$; see Appendix for further details).
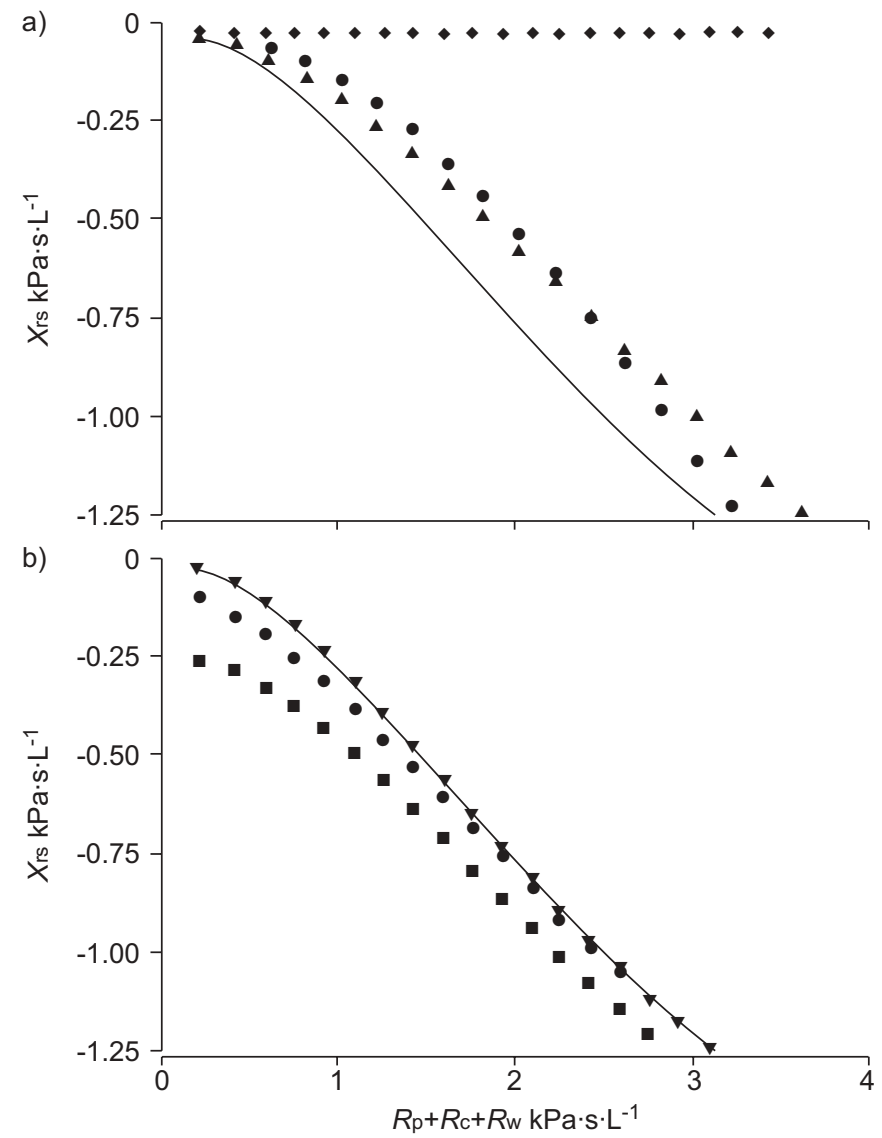

FIGURE 7. a) Relative importance of three mechanisms (heterogeneous parallel pathways $(\boldsymbol{\bullet})$ and upper $(\boldsymbol{\Delta})$ and central $(\boldsymbol{\bullet})$ airway wall shunting) contributing to the relationship between respiratory system reactance $\left(X_{r s}\right)$ and resistance (expressed as the sum of the serial resistance values of the lumpedelement model; peripheral airway resistance $(R p)+$ central airway resistance $(R c)+$ chest wall resistance $(R w)$ ), illustrated by repeating the simulations with the three effects combined (-) and in isolation. b) Simulation of the effect on the relationship between $X_{r s}$ and the sum of the serial resistances of the lumpedelement model $(R p+R c+R w)$ of changes in the static elastance of the lungs or chest wall. Normal static elastance $(-)$ is compared with a five-fold decrease in lung elastance ( $\mathbf{\nabla}$; compliant lungs), a five-fold increase in lung elastance ( $\mathbf{\bullet}$; stiff lungs) and a five-fold increase in chest wall elastance ( $\boldsymbol{\square}$; stiff chest wall).

contrast, introducing either upper or central airway wall shunt produced marked effects on Xrs, causing it to decrease as Rrs increased. Initially, both effects were of the same order of magnitude, but, at high levels of Xrs, the central airway wall shunt became relatively more important. The conclusion from these simulations is that both central and upper airway wall shunting are the major mechanisms dictating the linear relationship between $X_{\mathrm{rs}}$ and $R \mathrm{~L}$ at $5 \mathrm{~Hz}$, and time-constant inhomogeneity has little effect. This conclusion should be viewed with a note of caution since, although it is in keeping with previous lumped-element modelling results [18, 30-34], it is at variance with those of approaches using different forms of model [27-29]. It is possible that the Otis effect indeed has more impact on Xrs than shown in the present simulations, but that the lumped-element model as implemented does not accurately reflect the in vivo phenomenon. 
Why do all of the subjects, regardless of the nature of their respiratory pathology, lie on the same curve? This result was not predicted as it was anticipated that lung diseases such as pulmonary fibrosis and chest wall disease would show elevated static elastances and, therefore, that the $X_{\mathrm{rs}}-R \mathrm{~L}$ curve would shift significantly downwards. One suggestion that might account for the observed behaviour is that the influence of $R \mathrm{~L}$ on $\mathrm{Xrs}$ is much larger than that due to static elastance, even when the latter is increased several-fold. This explanation was supported by a further simulation (fig. 7b). First, lung elastance was decreased by a factor of five to simulate COPD (compliant lungs), which resulted in a small absolute increase in Xrs. Then, elastances were increased by a factor of five, first for the lungs (stiff lungs) and then for the chest wall (stiff chest wall), to simulate ILD and chest wall disease, respectively. The increased static elastances shifted the Xrs curve downwards, but not greatly. The largest effect occurred at low resistances, where the change was in the order of $-0.25 \mathrm{kPa} \cdot \mathrm{s} \cdot \mathrm{L}^{-1}$, whereas, at higher resistances, a change of only $-0.1 \mathrm{kPa} \cdot \mathrm{s} \cdot \mathrm{L}^{-1}$ was seen. In retrospect, this behaviour is also seen in the experimental data. Examining figure 4, Xrs tended to be more negative than the group results in subjects with chest wall disease and ILD, and less negative than in the group of subjects with COPD.

Do these findings further the understanding and widen the potential applications of the FOT? The present results and accompanying simulation suggest that, at $5 \mathrm{~Hz}, \mathrm{Xrs}$ is not a measure of a mechanical property such as elastance or inertance. Its value is instead mostly dictated by the balance between airway resistance and central and upper airway wall shunting. As a consequence, and as shown in the present study, mean Xrs,I measured at $5 \mathrm{~Hz}$ can provide a more accurate index of bronchoconstriction (measured here by RL) than Rrs. An additional advantage is that the relative change in $\mathrm{Xrs}$ during bronchoprovocation is greater than that in either FEV1 or Rrs. For example, for a $40 \%$ decrease in FEV1, mean \pm SD Rrs increased by a factor of $3.0 \pm 0.8$ and $\mathrm{Xrs}$ by $6.5 \pm 2.8$. This greater sensitivity is counterbalanced to a degree by worse repeatability, with the coefficients of variation of $R \mathrm{rs}$ and $X \mathrm{rs}$ being 11 and 17\%, respectively, in the present study. Although this does not make $\mathrm{Xrs}$ assessment a candidate for routine replacement of FEV1 measurement, especially in bronchoprovocation testing, it may have greater impact in other areas such as reversibility testing in COPD. Further, the relationship between $\mathrm{Xrs}$ and $\mathrm{RL}$ from figure $2 \mathrm{~b}$ provides information that can be derived from $R \mathrm{~L}$ which was previously only available with invasive measurement. One such example is resistive work of breathing, which can be calculated from $V^{\prime}$ and $R \mathrm{~L}$.

Finally, the present results complement the recent study of DELLACÀ et al. [35], which showed that expiratory reactance of the respiratory system can be used to demonstrate the presence of expiratory flow limitation. From the present study, mean inspiratory reactance of the respiratory system is the best predictor of inspiratory transpulmonary resistance. The present authors suggest that the usefulness of respiratory system reactance as a clinical outcome measure in airways obstruction should be more systematically assessed.

\section{APPENDIX}

Figure 8 shows the lumped-element model used in the simulation. It is similar to that used elsewhere [38]. Upper

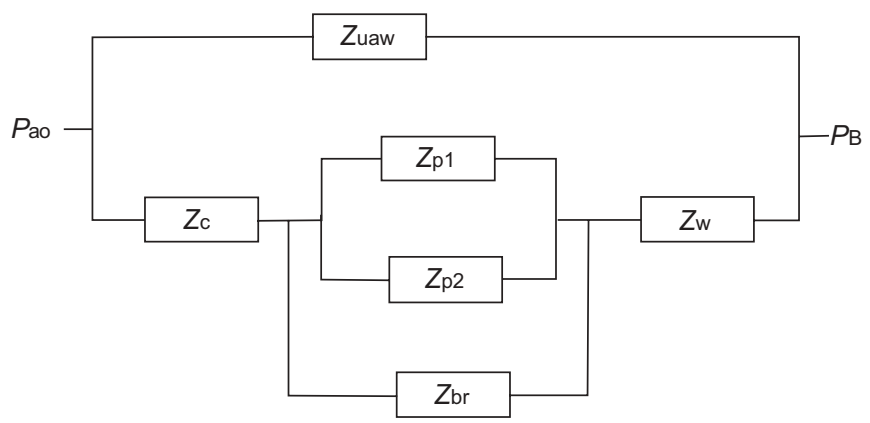

FIGURE 8. Lumped-element model used in the simulation. Upper airway (Zuaw) and bronchial (Zbr) impedance represent the shunting effect of the upper and central airway walls, respectively. Airway impedance is split into central $\left(Z_{c}\right)$ and parallel peripheral $(Z \mathrm{p} 1$ and $Z \mathrm{p} 2)$ components. $Z \mathrm{w}$ : chest wall impedance; $P$ ao: airway opening pressure; $P \mathrm{~B}$ : barometric pressure.

airway (Zuaw) and bronchial (Zbr) impedance represent the shunting effect of the upper and central airway walls, respectively. Holding the cheeks was simulated by doubling the quoted value of Zuaw [18]. Airway impedance is split into central $\left(Z_{c}\right)$ and peripheral $\left(Z_{\mathrm{p} 1}\right.$ and $\left.Z_{\mathrm{p} 2}\right)$ components. Two peripheral airway tissue pathways are included to allow for heterogeneous time constants. Zrs was obtained from the following expression:

$$
\mathrm{Z}_{\mathrm{rs}}=\mathrm{Zuaw}_{\mathrm{t}} /\left(\mathrm{Zuaw}_{\mathrm{u}}+\mathrm{Z}_{\mathrm{t}}\right)(2)
$$

where:

$$
Z_{t}=Z_{c}+\left(Z_{p 1} Z_{p} 2 Z_{b r} /\left(Z_{p} 1 Z_{p 2}+Z_{p} 1 Z_{b r}+Z_{p 2} Z_{b r}\right)\right)+Z_{w}
$$

and $Z_{w}$ is chest wall impedance.

The model neglects gas compressibility, as this is unlikely to be a significant effect at $5 \mathrm{~Hz}$, and viscoelasticity is represented as a simple compliance included in the value of the peripheral compliance.

Representative values for the model components were obtained from the literature and are summarised in table 3 . In describing the model, compliance (the reciprocal of elastance) is used, as this has been the convention in previous

\begin{tabular}{|c|c|c|c|c|}
\hline \multirow[t]{2}{*}{ TAB } & \multicolumn{4}{|c|}{$\begin{array}{l}\text { Parameter values used in lumped-element } \\
\text { simulations }\end{array}$} \\
\hline & $\begin{array}{l}\text { Resistance } \\
\mathrm{kPa} \cdot \mathbf{S} \cdot \mathrm{L}^{-1}\end{array}$ & $\begin{array}{l}\text { Inertance } \\
\mathrm{kPa} \cdot \mathbf{s}^{2} \cdot \mathrm{L}^{-1}\end{array}$ & $\begin{array}{l}\text { Compliance } \\
\mathrm{L} \cdot \mathrm{kPa}^{-1}\end{array}$ & $\begin{array}{l}\text { First author } \\
\text { [Ref.] }\end{array}$ \\
\hline Zuaw & 0.8 & 0.0034 & 0.014 & PESLIN [41] \\
\hline Zc & 0.07 & 0.002 & & \\
\hline $\begin{array}{l}Z \mathrm{p} 1 \\
Z \mathrm{p} 2\end{array}$ & \multirow[t]{2}{*}{ See Appendix } & & 1.7 & HANTOS [42] \\
\hline Zbr & & & 0.005 & See Appendix \\
\hline$Z_{w}$ & 0.05 & & 0.5 & HANTOS [42] \\
\hline
\end{tabular}
studies, making values easier to compare. Impedance $(Z)$ for 
any component of the model was derived from resistance $(R)$, inertance $(I)$ and compliance $(C)$ using the expression:

$$
\mathrm{Z}=R+i(\omega I-1 / \omega C)
$$

where $i=\sqrt{ }-1, \omega=2 \pi f$ and $f$ is frequency. Zbr was assumed to be a pure compliance ( $\mathrm{Cbr}$ ). The value often used for this parameter is $0.05 \mathrm{~L} \cdot \mathrm{kPa}^{-1}$, this being the estimate made by Mead from changes in the volume of the anatomical dead space and airway transmural pressures [26]. In the present model, this value appeared to be too large for several reasons. Its original derivation included the entire dead space, it was greater than the measured compliance of the supraglottal airway wall $\left(0.014 \mathrm{~L} \cdot \mathrm{kPa}^{-1}\right)$ and it produced simulation results that did not show the correct qualitative behaviour in terms of either Rrs or Xrs. Several studies in which parameters were fitted to a similar model have resulted in estimates of a smaller value for $C b r$, in the range $0.002-0.02 \mathrm{~L}^{\circ} \mathrm{kPa}^{-1}[33,39,40]$, and, hence, a value in this range $\left(0.005 \mathrm{~L} \cdot \mathrm{kPa}^{-1}\right)$ was used in the present simulation.

In order to reproduce the effect of bronchoconstriction, $R \mathrm{p} 1$ and $R \mathrm{p} 2$ were increased from a baseline of $R \mathrm{p} 1=R \mathrm{p} 2=0.2 \mathrm{kPa} \cdot \mathrm{s} \cdot \mathrm{L}^{-1}$ to a maximum combined value of $3.4 \mathrm{kPa} \cdot \mathrm{s} \cdot \mathrm{L}^{-1}$. Heterogeneous airways obstruction was created by increasing $R$ p2, while maintaining a fixed relationship between $R \mathrm{p} 1$ and $R \mathrm{p} 2$ as follows:

$$
R_{\mathrm{p} 1}=5 R_{\mathrm{p} 2}-0.8
$$

where $0.2 \leqslant R \mathrm{p} 2 \leqslant 4.0 \mathrm{kPa} \cdot \mathrm{s} \cdot \mathrm{L}^{-1}$. The peripheral compliance of $1.7 \mathrm{~L} \cdot \mathrm{kPa}^{-1}$ was divided equally between the two pathways. Repeating the simulation without either the upper or central airway wall shunt was achieved by removing Zuaw and Zbr, respectively. Removing the effect of parallel pathways was achieved by amalgamating $Z \mathrm{p} 1$ and $Z_{\mathrm{p} 2}$ into a single pathway with a baseline resistance of $0.1 \mathrm{kPa} \cdot \mathrm{s} \cdot \mathrm{L}^{-1}$ and compliance of $1.7 \mathrm{~L} \cdot \mathrm{kPa}^{-1}$. In order to simulate decreased static compliance of the lungs (stiff lungs) and chest wall (stiff chest wall), the compliances used to calculate $Z_{\mathrm{p} 1}, Z_{\mathrm{p} 2}$ and $Z_{\mathrm{w}}$ were decreased by a factor of five. In order to simulate more compliant lungs, compliance in $\mathrm{Zp}$ 1 and $\mathrm{Zp} 2$ was increased by a factor of five.

\section{ACKNOWLEDGEMENTS}

The authors would like to thank N. Pride for advice throughout this work.

\section{REFERENCES}

1 Oostveen E, Macleod D, Lorino $\mathrm{H}$, et al. The forced oscillation technique in clinical practice: methodology, recommendations and future developments. Eur Respir J 2003; 22: 1026-1041.

2 Phagoo SB, Watson RA, Silverman M, Pride NB. Comparison of four methods of assessing airflow resistance before and after induced airway narrowing in normal subjects. J Appl Physiol 1995; 79: 518-525.

3 Van Noord JA, Smeets J, Clement J, Van de Woestijne KP, Demedts M. Assessment of reversibility of airflow obstruction. Am J Respir Crit Care Med 1994; 150: 551-554.

4 Van Noord JA, Clement J, Van de Woestijne KP, Demedts $\mathrm{M}$. Total respiratory resistance and reactance as a measurement of response to bronchial challenge with histamine. Am Rev Respir Dis 1989; 139: 921-926.

5 Farre R, Peslin R, Rotger M, Barbera JA, Navajas D. Forced oscillation total respiratory resistance and spontaneous breathing lung resistance in COPD patients. Eur Respir J 1999; 14: 172-178.

6 Farre R, Rotger M, Marchal F, Peslin R, Navajas D. Assessment of bronchial reactivity by forced oscillation admittance avoids the upper airway artefact. Eur Respir J 1999; 13: 761-766.

7 Van Noord JA, Clement J, Van de Woestijne KP, Demedts $\mathrm{M}$. Total respiratory resistance and reactance in patients with asthma, chronic bronchitis, and emphysema. Am Rev Respir Dis 1991; 143: 922-927.

8 Malmberg LP, Mieskonen S, Pelkonen A, Kari A, Sovijarvi AR, Turpeinen M. Lung function measured by the oscillometric method in prematurely born children with chronic lung disease. Eur Respir J 2000; 16: 598-603.

9 Hellinckx J, De Boeck K, Demedts M. No paradoxical bronchodilator response with forced oscillation technique in children with cystic fibrosis. Chest 1998; 113: 55-59.

10 British Thoracic Society, National Asthma Campaign, Royal College of Physicians of London in association with the General Practitioner in Asthma Group, British Association of Accident and Emergency Medicine, British Paediatric Respiratory Society, Royal College of Paediatrics and Child Health: The British guidelines on asthma management 1995 review and position statement. Thorax 1997; 52: Suppl. 1, S1-S20.

11 Anon. BTS guidelines for the management of chronic obstructive pulmonary disease. Thorax 1997; 52: Suppl. 5, S1-S28.

12 Sterk PJ, Fabbri LM, Quanjer PhH, et al. Airway responsiveness. Standardized challenge testing with pharmacological, physical and sensitizing stimuli in adults. Eur Respir J 1993; 6: Suppl. 16, 53-83.

13 Baydur A, Behrakis PK, Zin WA, Jaeger M, Milic-Emili J. A simple method for assessing the validity of the esophageal balloon technique. Am Rev Respir Dis 1982; 126: 788-791.

14 Officer TM, Pellegrino R, Brusasco V, Rodarte JR. Measurement of pulmonary resistance and dynamic compliance with airway obstruction. J Appl Physiol 1998; 85: 1982-1988.

15 Davis GM, Stocks J, Gerhardt T, Abbasi S, Gappa M. Measurement of dynamic lung mechanics in infants. In: Stocks J, Sly PD, Tepper R, Morgan W, eds. Infant Respiratory Function Testing. New York, Wiley-Liss Inc., 1996.

16 Birch M, Macleod D, Levine M. An analogue instrument for the measurement of respiratory impedance using the forced oscillation technique. Physiol Meas 2001; 22: 323-339.

17 Horowitz JG, Siegel SD, Primiano FP Jr, Chester EH. Computation of respiratory impedance from forced sinusoidal oscillations during breathing. Comput Biomed Res 1983; 16: 499-521.

18 Michaelson ED, Grassman ED, Peters WR. Pulmonary mechanics by spectral analysis of forced random noise. $J$ Clin Invest 1975; 56: 1210-1230.

19 Bland JM, Altman DG. Statistical methods for assessing agreement between two methods of clinical measurement. Lancet 1986; 1: 307-310. 
20 Wouters EF, Verschoof AC, Polko AH, Visser BF. Impedance measurements of the respiratory system before and after salbutamol in COPD patients. Respir Med 1989; 83: 309-313.

21 Klug B, Bisgaard $H$. Measurement of lung function in awake 2-4-year-old asthmatic children during methacholine challenge and acute asthma: a comparison of the impulse oscillation technique, the interrupter technique, and transcutaneous measurement of oxygen versus wholebody plethysmography. Pediatr Pulmonol 1996; 21: 290-300.

22 Bouaziz N, Beyaert C, Gauthier R, Monin P, Peslin R, Marchal F. Respiratory system reactance as an indicator of the intrathoracic airway response to methacholine in children. Pediatr Pulmonol 1996; 22: 7-13.

23 Guerin C, Coussa ML, Eissa NT, et al. Lung and chest wall mechanics in mechanically ventilated COPD patients. $J$ Appl Physiol 1993; 74: 1570-1580.

24 Marshall R. Stress relaxation in the human lung. Clin Sci 1961; 20: 19-31.

25 Otis $\mathrm{AB}$, McKerrow CB, Bartlett RA, et al. Mechanical factors in distribution of pulmonary ventilation. J Appl Physiol 1956; 8: 427-443.

26 Mead J. Contribution of compliance of airways to frequencydependent behavior of lungs. J Appl Physiol 1969; 26: 670-673.

27 Lutchen KR, Greenstein JL, Suki B. How inhomogeneities and airway walls affect frequency dependence and separation of airway and tissue properties. J Appl Physiol 1996; 80: 1696-1707.

28 Lutchen KR, Gillis H. Relationship between heterogeneous changes in airway morphometry and lung resistance and elastance. J Appl Physiol 1997; 83: 1192-1201.

29 Anafi RC, Beck KC, Wilson TA. Impedance, gas mixing, and bimodal ventilation in constricted lungs. J Appl Physiol 2003; 94: 1003-1011.

30 Pimmel RL, Tsai MJ, Winter DC, Bromberg PA. Estimating central and peripheral respiratory resistance. J Appl Physiol 1978; 45: 375-380.

31 Nagels J, Landser FJ, van der Linden L, Clement J, Van de Woestijne KP. Mechanical properties of lungs and chest wall during spontaneous breathing. J Appl Physiol 1980; 49 408-416.

32 Ying Y, Peslin R, Duvivier C, Gallina C, Felicio D, Silva J. Respiratory input and transfer mechanical impedances in patients with chronic obstructive pulmonary disease. Eur Respir J 1990; 3: 1186-1192.

33 Peslin R, Felicio DS, Duvivier C, Chabot F. Respiratory mechanics studied by forced oscillations during artificial ventilation. Eur Respir J 1993; 6: 772-784.

34 Kaczka DW, Ingenito EP, Suki B, Lutchen KR. Partitioning airway and lung tissue resistances in humans: effects of bronchoconstriction. J Appl Physiol 1997; 82: 15311541.

35 Dellacà RL, Santus $\mathrm{P}$, Aliverti A, et al. Detection of expiratory flow limitation in COPD using the forced oscillation technique. Eur Respir J 2004; 23: 232-240.

36 Mitzner W, Blosser S, Yager D, Wagner E. Effect of bronchial smooth muscle contraction on lung compliance. J Appl Physiol 1992; 72: 158-167.

37 Peslin R, Duvivier C. Partitioning of airway and respiratory tissue mechanical impedances by body plethysmography. J Appl Physiol 1998; 84: 553-561.

38 Marchal F, Mazurek H, Habib M, Duvivier C, Derelle J, Peslin R. Input respiratory impedance to estimate airway hyperreactivity in children: standard method versus head generator. Eur Respir J 1994; 7: 601-607.

39 Farre R, Peslin R, Oostveen E, Suki B, Duvivier C, Navajas D. Human respiratory impedance from 8 to $256 \mathrm{~Hz}$ corrected for upper airway shunt. J Appl Physiol 1989; 67: 1973-1981.

40 Rotger M, Farre R, Navajas D, Peslin R. Respiratory input impedance up to $256 \mathrm{~Hz}$ in healthy humans breathing foreign gases. J Appl Physiol 1993; 75: 307-320.

41 Peslin R, Duvivier C, Gallina C, Cervantes P. Upper airway artifact in respiratory impedance measurements. Am Rev Respir Dis 1985; 132: 712-714.

42 Hantos Z, Daroczy B, Suki B, Galgoczy G, Csendes T. Forced oscillatory impedance of the respiratory system at low frequencies. J Appl Physiol 1986; 60: 123-132. 